\title{
Pesquisa em Educação do Campo: produção de conhecimento na diversidade
}

\author{
Cícero da Silva ${ }^{1}$, Gustavo Cunha de Araújo ${ }^{2}$ \\ ${ }^{1}$ Universidade Federal do Tocantins - UFT, Departamento de Educação do Campo, Avenida Nossa Senhora de \\ Fátima, 1588, Tocantinópolis, Brasil. rbec@uft.edu.br. ${ }^{2}$ Universidade Federal do Tocantins - UFT.
}

A Revista Brasileira de Educação do Campo - RBEC, ISSN 2525-4863, periódico do Departamento de Educação do Campo, da Universidade Federal do Tocantins, campus de Tocantinópolis, lança o primeiro número do volume 2 , que compreende o período entre janeiro e junho de 2017. Seguindo a política editorial e o escopo da revista, esta edição traz 20 artigos aprovados dentre os recebidos no período de submissão (de outubro de 2016 a fevereiro de 2017), além de uma Resenha. Não podemos deixar de registrar a presença de 3 artigos e uma resenha em Espanhol neste número, todos de autoria de pesquisadores de outros países da América Latina, como Cuba, México e Colômbia, o que reforça a ampliação de pesquisas a respeito da Educação do Campo não apenas no Brasil, mas também em outros países.

No intuito de acelerar a divulgação dos artigos recebidos, avaliados, revisados e aprovados pela revista, dentro de cada edição (jan./jun e jul./dez.), a partir de março de 2017 a RBEC adotou a Publicação Avançada de Artigos (PAA), também conhecida como Ahead of Print (AOP). Além de ser uma prática bastante utilizada por diferentes periódicos nacionais e internacionais, possibilita a divulgação em menor espaço de tempo dos artigos indexados nas bases de dados para pesquisa. Mas a conquista mais importante da RBEC em seu primeiro aniversário foi o Qualis Capes 2016, tendo alcançado B1 - Ensino, B2 - Educação, B4 Antropologia/Arqueologia, B4 - Interdisciplinar e B5 - Letras/Linguística. Pelos resultados obtidos, nosso agradecimento especial aos colegas, autores(as) dos artigos, pareceristas e avaliadores ad hoc que acreditaram e apoiaram a revista.

O conjunto de artigos publicados neste número da RBEC corrobora a diversidade de pesquisas em educação desenvolvidas em diferentes contextos, tendo como objeto de estudo a Educação do Campo. Considerando a importância do fortalecimento dessa modalidade de ensino para os povos do campo, os temas dos trabalhos comtemplam: formação de professores das escolas do campo, práticas pedagógicas em Educação do Campo, educação popular e interfaces com a Educação do Campo, conhecimento tradicional, currículo e ensino no meio rural, pluralismo cultural, sistema educativo e inclusão social, práticas educativas e movimentos sociais, políticas públicas para Educação do Campo, entre outros.

Iniciamos a apresentação dos artigos desta edição com o trabalho intitulado "La formación del maestro primario rural", da pesquisadora Grandal, vinculada à Universidad de Artemisa, Cuba, que, a partir de uma pesquisa realizada nas escolas rurais cubanas, reflete sobre a pesquisa educacional no processo de formação de professores dessas instituições, constatando que a abordagem de investigação no processo de formação docente foi aprovada 
pelo Ministério de Educação de Cuba e será utilizada nas escolas rurais, com o objetivo de melhorar a formação dos professores cubanos.

O segundo artigo, "Projetos pedagógicos nas escolas comunitárias do Espírito Santo: propostas que se somam a educação do campo", é de autoria dos pesquisadores Pereira e Fernandes, da Universidade Federal Rural do Rio de Janeiro (UFRRJ). Nesta pesquisa, são analisados dois projetos pedagógicos desenvolvidos na escola municipal de ensino fundamental Pedra Torta, situada no município de Águia Branca-ES. Esse tipo de unidade educativa também é conhecido como Escola Comunitária Agroecológica e apresenta uma nova ideia de escola que assume a alternância nas práticas formativas, fora do eixo das Escolas Famílias Agrícolas (EFA). Trata-se de um modelo de educação que objetiva valorizar a cultura do campo, o cultivo da terra, a qualidade de vida e o equilíbrio harmônico do ambiente. Os resultados da pesquisa revelaram que as experiências formativas na escola focalizada possibilitam a percepção das diversas dimensões da realidade rural e a valorização da cultura do campo.

Já o artigo "Os processos formativos dos estudantes da LEC/UFES: um olhar com/pelos Cadernos da Realidade”, das autoras Luiz e Alcântara, ambas da Universidade Federal do Espírito Santo (UFES), apresenta resultados parciais de uma pesquisa a respeito da produção de saberes por estudantes do curso de Licenciatura em Educação do Campo da UFES. Nesse estudo, os processos formativos dos discentes são analisados com base nos registros do Caderno da Realidade, um instrumento didático-pedagógico fundamental da Pedagogia da Alternância. Os resultados preliminares da pesquisa evidenciaram a potencialidade, via Cadernos da Realidade, dos estudos desenvolvidos no TempoUniversidade e da pesquisa empreendida no Tempo-Comunidade, no sentido de que esses momentos favorecem a qualificação da formação docente.

$\mathrm{Na}$ sequência, temos o artigo "Notas sobre práticas educativas diferenciadas no MST: os princípios pedagógicos revelados a partir de algumas metodologias empregadas na educação do movimento", da professora Da Mata, egressa do Mestrado em Educação da UNESP/Marília e professora da Secretaria Municipal de Educação de São Paulo, que em seu texto, afirma que esses princípios e práticas são importantes para uma aprendizagem ao longo da vida, pautada pela formação humana e política. A autora conclui, com base nos resultados da pesquisa, que o MST valoriza o contexto dos sujeitos crianças, jovens e adultos que vivem no campo, nos diversos processos de aprendizagem.

Em "O Movimento dos Pequenos Agricultores na interface entre agricultura familiar e educação do campo", Santos e Richard, vinculados à Universidade Federal Rural do Rio de Janeiro (UFRRJ), abordam o protagonismo do Movimento dos Pequenos Agricultores (MPA), em relação à agricultura familiar e Educação do Campo. O objetivo da pesquisa é conhecer o plano camponês, uma das principais "armas" do MPA. Com base nos resultados do estudo, os autores concluem que o processo de ensino e aprendizagem pode dialogar com a realidade concreta dos sujeitos, individuais e coletivos, articulados com a luta pela terra. Por sua vez, a produção coletiva do saber em parceria com educandos(as), educadores(as), comunidades e os movimentos sociais de luta pela terra, pode dialogar com histórias, memórias, identidades, desejos, valores e reconhecimento, fortalecendo o debate em torno da Educação do Campo, na sua estreita relação com movimentos sociais, escolas do campo e universidades públicas.

De autoria da professora Silva, do Instituto Federal de Educação, Ciência e Tecnologia de Goiás (IFG), o artigo intitulado "Morar no meio rural: o cotidiano dos/as jovens rurais de um município baiano" tem o objetivo de entender as percepções dos/das jovens que vivem no meio rural e as experiências construídas por esses sujeitos nesse espaço. A pesquisa constatou que as políticas públicas desenvolvidas devem ser articuladas com o contexto rural como lugar de vida, trabalho, cultura e lazer. 
$O$ artigo denominado "A confecção de bonecas negras na formação de professores", das autoras Rosa e Ferreira, ambas vinculadas à Universidade Federal do Rio Grande (FURG), traz uma experiência formativa de professores que contempla o desenvolvimento de oficinas com o fito de confeccionar bonecas negras, sendo a oficineira uma estudante quilombola. A proposta das oficinas era empoderar estudantes, mulheres negras e quilombolas por meio da confecção dessas bonecas, que simbolizam a identidade negra. Ao concluir o trabalho, as autoras afirmam que a confecção de bonecas negras, embasada por teorias que visam valorizar os povos tradicionais, especialmente os quilombolas, em diálogo com a educação popular, vai além de uma técnica arte, trata-se de um (re)olhar para si e para as questões étnico-sociais.

Em seguida, o artigo "Conhecimentos tradicionais em torno das plantas medicinais e currículo do ensino de ciências", de autoria das pesquisadoras Moreno e Silva da Universidade Federal do Sul e Sudeste do Pará (UNIFESSPA), tem por objetivo compreender a relação entre o conhecimento tradicional sobre as plantas medicinais e o uso de medicamentos farmacêuticos pelos moradores de uma comunidade camponesa maranhense. As autoras concluíram que o desenvolvimento de novas práticas de ensino e aprendizagem a partir da realidade do educando contribui para que o ensino de Ciências na Educação do Campo enriqueça esse processo de ensino e aprendizagem, possibilitando uma interação mais dialógica entre alunos e professores.

Já o artigo "Educação infantil no campo e os avanços no aspecto legal: reconhecimento da educação como direito social para as crianças camponesas", de autoria de Moreira, Rosa e Oliveira, vinculados à Universidade do Estado da Bahia (UNEB) e ao Instituto Federal de Educação, Ciências e Tecnologia Baiano (IFBAIANO), focaliza a educação infantil do campo, partindo-se da seguinte questão: como o aporte jurídico que orienta a educação tem contemplado as questões inerentes à educação infantil do campo, sobretudo a partir de 1998? Com base no estudo de leis e diretrizes da educação, os autores concluem que a Educação do Campo, em particular a primeira etapa da educação básica, já se faz significativamente presente nas leis e diretrizes. Entretanto, ainda existem grandes lacunas para serem superadas a fim de que as crianças camponesas sejam plenamente reconhecidas como sujeitos de direitos.

Outro artigo internacional publicado neste número pode ser consultado no texto: "Las escuelas rurales de La Habana: un problema sin resolver en la República Neocolonial entre 1936 y 1952", do pesquisador Castilho, da Universidad de Artemisa, Cuba. O autor desvela as condições materiais e psicológicas que professores desenvolvem em suas aulas, constatando que, dentre outros resultados, os currículos e programas de escolas rurais em Havana apresentam soluções para alguns problemas educacionais existentes no ensino ofertado por essas instituições; no entanto, vários dos regulamentos que essas escolas implantaram não foram capazes de materializar toda a amplitude do ensino devido à negligência dos governos republicanos, embora as suas contribuições para a pedagogia e a didática tenham sido significativas.

No artigo intitulado "De la organización campesina a la irrupción indígena zapatista en Chiapas, México: un aprendizaje político para el pluralismo cultural”, dos pesquisadores López, Romero e Romero, da Universidad Intercultural de Chiapas, México, encontramos reflexões acerca da organização dos indígenas mexicanos, cujo processo organizacional envolveu autoaprendizagem política dentro da perspectiva epistemológica da diversidade cultural. No primeiro momento, tal mobilização é marcada pela dependência e subordinação ao Estado e a sua teoria indígena. Em seguida, são estabelecidas organizações indígenas independentes que lutam pela regularização da posse da terra, denunciam a miséria indígena e defendem o respeito aos seus direitos humanos. Na década de 1990, a luta indígena alcançou uma dimensão qualitativa: foi exigida pelo Exército Zapatista de Libertação

\begin{tabular}{|l|l|l|l|l|l|l|l|}
\hline Rev. Bras. Educ. Camp. & Tocantinópolis & v. 2 & n. 1 & p. 01-06 & jan./jun. & 2017 & ISSN: 2525-4863 \\
\hline
\end{tabular} 
Nacional autonomia comunal e municipal para acessar a uma nova visão de estado centrado na realidade multiétnica da nação. Ao concluir, os autores destacam que o desenvolvimento contribuiu para uma política de autoaprendizagem indígena de pluralismo cultural, o que levou o Estado a conviver com um movimento hostil que permanece latente, até hoje, no sudeste do México.

De autoria das pesquisadoras Guimarães e Gonçalves, ambas do Centro Federal de Educação Tecnológica de Minas Gerais (CEFET), o artigo "Relações de gênero e divisão sexual do trabalho no meio rural: interlocuções com o movimento social "Marcha das Margaridas" problematiza as relações de gênero e a divisão sexual do trabalho no meio rural em diálogo com o movimento social "Marcha das Margaridas". As colaboradoras da pesquisa são mulheres produtoras rurais, do norte do Estado de Minas Gerais, participantes da referida Marcha. Os resultados da investigação revelaram que, embora existam situações de desigualdades e a invisibilidade das mulheres presentes no trabalho no meio rural - com a permanência do "trabalho múltiplo", a participação e o engajamento em movimentos sociais de base feminista e rural, tais como a "Marcha das Margaridas", têm contribuído para a quebra de paradigmas enraizados na sociedade. Evidenciam-se alterações na forma de pensar e de ver o mundo, bem como na prática social, o que traz conquistas substanciais para as mulheres camponesas.

No artigo "Os educadores na educação do campo e as suas condições de trabalho docente", de autoria de Bitencourt e Zart, da Universidade do Estado de Mato Grosso (UNEMAT), os autores buscam refletir a respeito das condições de trabalho de professores da Educação do Campo para realização de práticas pedagógicas adequadas a esse contexto, de uma região de fronteira entre Brasil e Bolívia. Foi evidenciado na pesquisa realizada que, mesmo sendo denominadas de escolas rurais pelo poder público, o mesmo não concebe adequadamente o que seja uma escola do campo ou, pelo menos, do que deveria ser uma escola que atenda a realidade camponesa de uma região rural.

Numa pesquisa realizada na região sul do Brasil, intitulada "Aprender a nossa língua vernácula": a imigração e educação (rural) no Folha do Oeste (1946-1960)", de autoria de Santos, da Universidade Federal da Fronteira Sul (UFFS), aborda a educação escolar e imigração no Paraná, entre 1946 a 1960. De acordo com os resultados da investigação, o autor constatou que a educação nessa época era considerada como rural, pois não se considerava os sujeitos do campo, sendo apenas uma questão de Estado para um controle social, promovendo um mínimo de instrução.

Como resultado de pesquisa realizada na Universidade Estadual de Mato Grosso do Sul e tendo como campo de estudo a Escola Família Agrícola de Sidrolândia-MS, no artigo "Educação popular e educação do/no campo: perspectivas para uma educação inclusiva - a Escola Família Agrícola em Sidrolândia - MS”, os autores Assunção e Bernardelli da Universidade do Estado do Mato Grosso do Sul (UEMS) buscaram compreender quais possibilidades os movimentos sociais poderiam desenvolver uma educação diferenciada, a partir ou não do aparato do Estado, produzindo conhecimento científico e importante intervenção efetiva na sua realidade e na prática pedagógica que melhor responde aos seus anseios, acontecendo uma educação no e para o campo.

Em seguida, temos o artigo "A educação escolar no meio rural do município de Ituiutaba-MG Brasil: Educação Rural ou Educação do Campo?”, de autoria de Silva Júnior e Leite, da Universidade Federal de Uberlândia (UFU), que tem como objetivo ressaltar a diferença entre Educação do Campo e Educação Rural. Os autores apresentam uma pesquisa desenvolvida em Minas Gerais, que revelou, dentre outros resultados, que a educação que se efetiva nas escolas rurais da região pesquisada se caracteriza como Educação Rural.

\begin{tabular}{|l|l|l|l|l|l|l|l|}
\hline Rev. Bras. Educ. Camp. & Tocantinópolis & v. 2 & n. 1 & p. 01-06 & jan./jun. & 2017 & ISSN: 2525-4863 \\
\hline
\end{tabular}


"Perspectivas dos atores ligados à vida acadêmica dos discentes em transição e adaptação escolar em assentamentos organizados pelo MST", de autoria de Silva, da Faculdade Escritor Osman da Costa Lins (FACOL), busca analisar o processo de transição e adaptação dos alunos das escolas rurais do MST para as escolas urbanas de Pernambuco. Dentre alguns resultados, afirma que as transições e adaptações escolares são sofridas e que há, desde uma possível acomodação, que pode até ser confundida com conivência, a limitações e falta de formação por parte dos atores responsáveis.

Em "Educação do Campo e políticas públicas no município de AbaetetubaPará", dos autores Pereira, Pureza e Haje, vinculados respectivamente à Secretaria Municipal de Educação de Abaetetuba (SEMEC) e à Universidade Federal do Pará (UFPA), o foco da pesquisa são as políticas públicas de Educação do Campo, desenvolvidas no Brasil, considerando as especificidades e peculiaridades do município de Abaetetuba, localizado no interior do Pará. Com base nos resultados, os autores concluem que o município de Abaetetuba encontra-se numa fase inicial de discussão e implementação de políticas voltadas para o atendimento dos sujeitos do campo, tendo os movimentos sociais e instituições de ensino superior locais assumido posição privilegiada como protagonistas nesse processo.

Já o artigo intitulado "Programa Mais Educação: diálogos partindo da percepção de pais de estudantes de uma comunidade rural", dos pesquisadores Justino e Sant'anna, vinculados respectivamente à Universidade Federal de Minas Gerais (UFMG) e à Universidade Federal dos Vales do Jequitinhonha e Mucuri (UFVJM), objetiva refletir sobre a forma como famílias camponesas de uma comunidade do interior de Minas Gerais compreendem o Programa Mais Educação (PME). Além disso, as análises também focalizam as possíveis relações entre o projeto de Educação Integral e os princípios da Educação do Campo. Segundo os autores, os resultados evidenciaram que os pais da comunidade pesquisada percebem que as atividades desenvolvidas no PME não implicam em um movimento de formação que contemple as realidades e necessidades dos sujeitos do campo.

No artigo "A licenciatura em Educação do Campo na Universidade Federal do Triângulo Mineiro: território de contradições”, de autoria dos pesquisadores Souza, Kato e Pinto, da Universidade Federal do Triângulo Mineiro (UFTM), tiveram como objetivo principal investigar as demandas formativas, considerando principalmente a dimensão da educação escolar, tendo como parâmetro o curso de Licenciatura em Educação do Campo da UFTM. Na pesquisa desenvolvida, os autores entendem que a região de abrangência dessa universidade possui escolas do campo, mas também professores leigos e um cenário de luta pela terra que, segundo os pesquisadores, geralmente é silenciado, desconsiderado e pouco compreendido.

Por fim, a Resenha do livro "EaD: diálogos, compartilhamentos, práticas e saberes" de Neves, Corradi e Castro (2016), elaborada pelos pesquisadores Villota, Enríquez e López, da Universidade Federal de São Carlos (UFSCAR) e Universidad Santiago de Cali, Colômbia, fecha esse número da RBEC. O trabalho apresenta relatos e práticas pedagógicas de pesquisas desenvolvidas sobre Educação a Distância $(\mathrm{EaD})$ a partir de diferentes temáticas e contextos de pesquisa.

Novamente, a Revista Brasileira de Educação do Campo, periódico científico da Universidade Federal do Tocantins, buscando ser um importante veículo científico para ampliar as pesquisas no que concerne a Educação do Campo no Brasil e em outros países, agradece aos autores(as) e avaliadores(as) que contribuíram nas emissões de pareceres e revisões dos trabalhos apresentados nesta edição. São temas que, embora sejam produzidos em diferentes contextos nacionais e internacionais em diálogo com diferentes áreas do conhecimento e objetos de estudos, reforçam a necessidade de se ampliar pesquisas sobre a Educação do Campo, contribuindo para a produção de conhecimento em educação.

\begin{tabular}{|l|l|l|l|l|l|l|l|}
\hline Rev. Bras. Educ. Camp. & Tocantinópolis & v. 2 & n. 1 & p. 01-06 & jan./jun. & 2017 & ISSN: 2525-4863 \\
\hline
\end{tabular} 
É importante destacar que a RBEC, em busca da qualidade e difusão científica, atualmente está indexada em importantes bases indexadoras nacionais e internacionais, que possibilitam uma maior inserção das pesquisas aqui apresentadas à comunidade acadêmica nacional e internacional. Como destaque, ressaltamos a indexação nas bases (Bases de Dados, Catálogos, Repositórios) DOAJ, EDUBASE, ERIHPLUS, CROSSREF, LATINDEX, PORTAL DE PERIÓDICOS DA CAPES, REDIB, ROAD, DIADORIM entre outras, as quais podem ser consultadas no site da revista.

Desejamos a todos e a todas boas leituras!

\section{Como citar este editorial / How to cite this editorial}

APA:

Silva, C., Araújo, G. C. (2017). Pesquisa em Educação do Campo: produção de conhecimento na diversidade. Rev. Bras. Educ. Camp., 2(1), 01-06.

\section{ABNT:}

SILVA, C.; ARAÚJO, G. C. Pesquisa em Educação do Campo: produção de conhecimento na diversidade. Rev. Bras. Educ. Camp., Tocantinópolis, v. 2, n. 1, p. 01-06, 2017. 